\title{
Biomimetic synthesis of antimicrobial silver nanoparticles using in vitro-propagated plantlets of a medicinally important endangered species: Phlomis bracteosa
}

This article was published in the following Dove Press journal:

International Journal of Nanomedicine

22 April 2016

Number of times this article has been viewed

\author{
Sumaira Anjum \\ Bilal Haider Abbasi \\ Department of Biotechnology, \\ Quaid-i-Azam University, \\ Islamabad, Pakistan
}

Correspondence: Bilal Haider Abbasi Department of Biotechnology,

Quaid-i-Azam University, Islamabad 45320, Pakistan

Tel +92 5l 90644 I I I

Fax +92 51 9064 4I2I

Email bhabbasi@qau.edu.pk

\begin{abstract}
In vitro-derived cultures of plants offer a great potential for rapid biosynthesis of chemical-free antimicrobial silver nanoparticles (AgNPs) by enhancing their phytochemical reducing potential. Here, we developed an efficient protocol for in vitro micropropagation of a high-value endangered medicinal plant species, Phlomis bracteosa, in order to explore its biogenic potential in biomimetic synthesis of antimicrobial AgNPs. Murashige and Skoog medium supplemented with $2.0 \mathrm{mg} / \mathrm{L}$ thidiazuron was found to be more efficient in inducing optimum in vitro shoot regeneration $(78 \% \pm 4.09 \%)$, and $2.0 \mathrm{mg} / \mathrm{L}$ indole-3-butyric acid was used for maximum root induction $(86 \% \pm 4.457 \%)$. Antimicrobial AgNPs were successfully synthesized by using aqueous extract (rich in total phenolics and flavonoids content) of in vitro derived plantlets of $P$. bracteosa. Ultraviolet-visible spectroscopy of synthesized AgNPs showed characteristic surface plasmon band in the range of 420-429 $\mathrm{nm}$. The crystallinity, size, and shape of the AgNPs were characterized by X-ray diffraction and scanning electron microscopy. Face-centered cubic AgNPs of almost uniform spherical size $(22.41 \mathrm{~nm})$ were synthesized within a short time (1 hour) at room temperature. Fourier-transform infrared spectroscopy revealed that the polyphenols were mainly responsible for reduction and capping of synthesized AgNPs. Energy dispersive X-ray analysis further endorsed the presence of elemental silver in synthesized AgNPs. These biosynthesized AgNPs displayed significantly higher bactericidal activity against multiple drug-resistant human pathogens. The present work highlighted the potent role of in vitro-derived plantlets of $P$. bracteosa for feasible biosynthesis of antimicrobial AgNPs, which can be used as nanomedicines in many biomedical applications.
\end{abstract}

Keywords: silver nanoparticles, Phlomis bracteosa, in vitro micropropagation, antimicrobial, multidrug resistant bacteria

\section{Introduction}

Biomimetic synthesis of nanoparticles is an area of immense interest due to its broader applicability in the fields of medicine, molecular biology, physics, electronics, and chemistry. ${ }^{1}$ Among various metallic nanoparticles, silver nanoparticles (AgNPs) are gaining particular attention due to their desirable properties, including their high surface-to-volume ratios, catalytic optical, biosensing, and antimicrobial effects. ${ }^{2,3}$ However, most techniques used for the synthesis of nanoparticles involved various chemicals, which are expensive and may adversely affect the environment and various biological systems. On the other hand, the "Green" methods of nanoparticle synthesis using biological entities such as bacteria, yeast, fungi, and plants are stated to be clean, 
nonhazardous, inexpensive, and environmentally tolerable when compared to other methods. ${ }^{4-6}$ In the literature, many reports are available on the toxicity of chemically produced AgNPs to eukaryotic cells and environment. ${ }^{7,8}$ The toxicity of AgNPs can be minimized by synthesizing them from plant extracts which do not involve the use of any external harsh chemicals, hence decreasing the toxicity of AgNPs. ${ }^{9}$ Synthesis of AgNPs using plant extracts is the most implemented method of green, eco-friendly fabrication of nanoparticles and also has a distinctive advantage that the plants are extensively distributed, less biohazardous, and act as a source of numerous antioxidant metabolites. ${ }^{10,11}$ These naturally occurring plant secondary metabolites possess strong reduction properties, which can be linked with the higher potential ability of plant extracts to synthesize chemical-free AgNPs with minimum toxic effects. ${ }^{1}$ Among different plant species, medicinal plants are of special concern since they control the size and shape of nanoparticles by providing capping layers to nanoparticles and also prevent them from agglomeration. ${ }^{12}$

Phlomis bracteosa (Lamiaceae), an endangered plant species, is traditionally used as herbal medicine for the treatment of bone fractures, sinus congestion, lymph fluid disorder, and indigestion. ${ }^{13,14}$ Leaves and flowers of $P$. bracteosa possess many pharmacological and biological properties such as antiglycation, antibacterial, antifungal, anti-inflammatory, immunosuppressive, antimutagenic, antinociceptive, antifebrile, immunomodulatory, antimalarial, and antioxidant. ${ }^{15-18}$ Various phytochemicals such as phenolics, flavonoids, terpenoids, saponins, and tannins have been reported in this species and these are responsible for its biological activities. ${ }^{19}$ But, unfortunately, this high-value medicinal plant has not received much attention from researchers, and now it has become an endangered species due to its overharvesting from the wild for medicinal use. Due to the presence of highly valuable phytochemicals, an efficient and reliable regeneration protocol is needed for genetic transformation, multiplication, and germplasm conservation of this commercially important plant species.

In vitro culture techniques offer a viable tool for rapid multiplication of elite clones of valuable endangered plant species. ${ }^{20-23}$ In some species it is difficult to determine the optimal conditions for sustainable growth, but in vitro micropropagation continues to be a reliable source for conservation of medicinally important endangered plant species. ${ }^{24}$ Due to strong antioxidant activity and presence of large amount of biologically active phytochemicals, P. bracteosa may be considered as a potential source for reduction of silver ions $\left(\mathrm{Ag}^{+}\right)$to AgNPs. So, here we developed an efficient protocol for in vitro regeneration of $P$. bracteosa, in order to explore its biogenic potential in biomimetic synthesis of antimicrobial AgNPs. The major goal of this study was to develop a safe, rapid, and cost-effective protocol for biomimetic synthesis of antimicrobial AgNPs using aqueous extract of in vitro propagated plantlets of $P$. bracteosa. In vitro antibacterial activities of synthesized AgNPs have also been investigated against multiple drugresistant bacterial strains. To the best of our information, this is the very first report on exploitation of $P$. bracteosa for the aforementioned objectives.

\section{Materials and methods Plant material and explant source}

Seeds of P. bracteosa were provided by Dr Nisar Ahmad, Assistant Professor at University of Swat, Pakistan. Seeds were surface sterilized according to the method of Ali et $\mathrm{a}^{25}$ with some modifications. Briefly, seeds were washed with running tap water for 10 minutes and then immersed in $1 \%$ mercuric chloride solution for 1 minute and in $70 \%$ ethanol for 2 minutes, followed by washing five times with autoclaved double distilled water. After that, seeds were carefully dried on sterilized filter papers inside a laminar flow bench and placed on Murashige and Skoog ${ }^{26}$ basal medium (MS0) containing $30 \mathrm{~g} / \mathrm{L}$ sucrose, and $8 \mathrm{~g} / \mathrm{L}$ agar as solidifying agent. The $\mathrm{pH}$ of all media was adjusted to 5.6 and autoclaved at $121^{\circ} \mathrm{C}$ for 20 minutes. Inoculated flasks were placed in growth chamber at $25^{\circ} \mathrm{C} \pm 2^{\circ} \mathrm{C}$ under $16 / 8$ hours photoperiod with light intensity of $40 \mu \mathrm{mol} / \mathrm{m}^{2} / \mathrm{s}$. After 25 days of inoculation, we collected stem explants from plantlets of $P$. bracteosa for shoot organogenesis.

\section{Shoot induction}

For shoot induction, $\sim 1-2 \mathrm{~cm}$ of stem explants lacking nodules were inoculated on MS0 media supplemented with varying concentration $(0.5,1.0,2.0,3.0,4.0$, and $5.0 \mathrm{mg} / \mathrm{L})$ of thidiazuron (TDZ), $\alpha$ naphthalene acetic acid (NAA), 6-benzylaminopurine (BA), and gibberellic acid $\left(\mathrm{GA}_{3}\right)$. The $\mathrm{pH}$ of all media was adjusted to 5.6-5.7 prior to autoclaving, and the cultures were maintained at $25^{\circ} \mathrm{C} \pm 2^{\circ} \mathrm{C}$ for $16 / 8$ hours photoperiod in growth chamber. MS0 medium without any plant growth regulators (PGRs) was used as control. After 4 weeks of inoculation, the efficacy of PGRs was determined by recording the frequency of shoot formation (\%), number of shoots developing per explant, and average shoot length $(\mathrm{cm})$.

\section{Rooting and acclimatization}

In vitro regenerated shoots $(3-5 \mathrm{~cm})$ lacking nodules were excised and transferred to MS0 medium supplemented with 
Table I Effects of IAA $(0.5-5.0 \mathrm{mg} / \mathrm{L})$ and IBA $(0.5-5.0 \mathrm{mg} / \mathrm{L})$ on root induction frequency, mean root length, and number of roots per plantlet in Phlomis bracteosa

\begin{tabular}{|c|c|c|c|c|}
\hline \multicolumn{5}{|c|}{ Root organogenesis } \\
\hline $\begin{array}{l}\text { Serial } \\
\text { number }\end{array}$ & PGRs treatments (mg/L) & $\begin{array}{l}\text { Root formation (\%) } \\
\text { (mean } \pm \text { SD) }\end{array}$ & $\begin{array}{l}\text { Mean root length }(\mathrm{cm}) \\
(\text { mean } \pm \mathrm{SD})\end{array}$ & $\begin{array}{l}\text { Number of roots/plantlet } \\
\text { (mean } \pm \text { SD) }\end{array}$ \\
\hline 1 & IAA 0.5 & $10 \pm 1.02$ & $I . I \pm 0.04$ & $2 \pm 0.11$ \\
\hline 2 & IAA I.0 & $27 \pm 1.12$ & $1.5 \pm 0.09$ & $3 \pm 0.26$ \\
\hline 3 & IAA 2.0 & $55 \pm 3.11$ & $2.2 \pm 0.14$ & $4 \pm 0.18$ \\
\hline 4 & IAA 3.0 & $59 \pm 2.37$ & $2.7 \pm 0.13$ & $6 \pm 0.26$ \\
\hline 5 & IAA 4.0 & $25 \pm 2.11$ & $1.8 \pm 0.12$ & $3 \pm 0.19$ \\
\hline 6 & IAA 5.0 & $12 \pm 1.02$ & $1.1 \pm 0.06$ & $2 \pm 0.21$ \\
\hline 7 & IBA 0.5 & $18 \pm 1.12$ & $1.6 \pm 0.09$ & $3 \pm 0.17$ \\
\hline 8 & IBA I.0 & $43 \pm 1.33$ & $1.9 \pm 0.18$ & $4 \pm 0.01$ \\
\hline 9 & IBA 2.0 & $86 \pm 4.45$ & $4.3 \pm 0.46$ & $9 \pm 0.33$ \\
\hline 10 & IBA 3.0 & $75 \pm 3.65$ & $3.3 \pm 0.37$ & $7 \pm 0.37$ \\
\hline 11 & IBA 4.0 & $64 \pm 1.99$ & $2.1 \pm 0.22$ & $5 \pm 0.24$ \\
\hline 12 & IBA 5.0 & $3 \mathrm{I} \pm 2.79$ & $1.7 \pm 0.18$ & $2 \pm 0.04$ \\
\hline 13 & MSO & - & - & - \\
\hline
\end{tabular}

Note: Values mean \pm SD indicate the replicates of three experiments.

Abbreviations: IAA, indole-3-acetic acid; IBA, indole-3-butyric acid; PGR, plant growth regulator; SD, standard deviation; MS0, Murashige and Skoog basal medium.

varying concentrations $(0.5,1.0,2.0,3.0,4.0$, and $5.0 \mathrm{mg} / \mathrm{L})$ of indole-3-butyric acid (IBA) and indole-3-acetic acid (IAA) (Table 1). After 4 weeks of culture, plantlets with well-developed roots were removed from the flasks, and after gentle washing of roots with tap water, the plantlets were placed into plastic cups filled with organic manure, clay soil, and sand $(1: 1: 1)$ at $25^{\circ} \mathrm{C} \pm 2{ }^{\circ} \mathrm{C}$ under $16 / 8$ hours photoperiod in growth chamber. Three weeks later, the plantlets were transplanted into garden soil for acclimatization.

\section{Extract preparation}

Before acclimatization, $\sim 10 \mathrm{~g}$ of in vitro-derived plantlets of P. bracteosa with well-developed roots were collected for extract preparation (Figure 1A). Briefly, the plantlets were
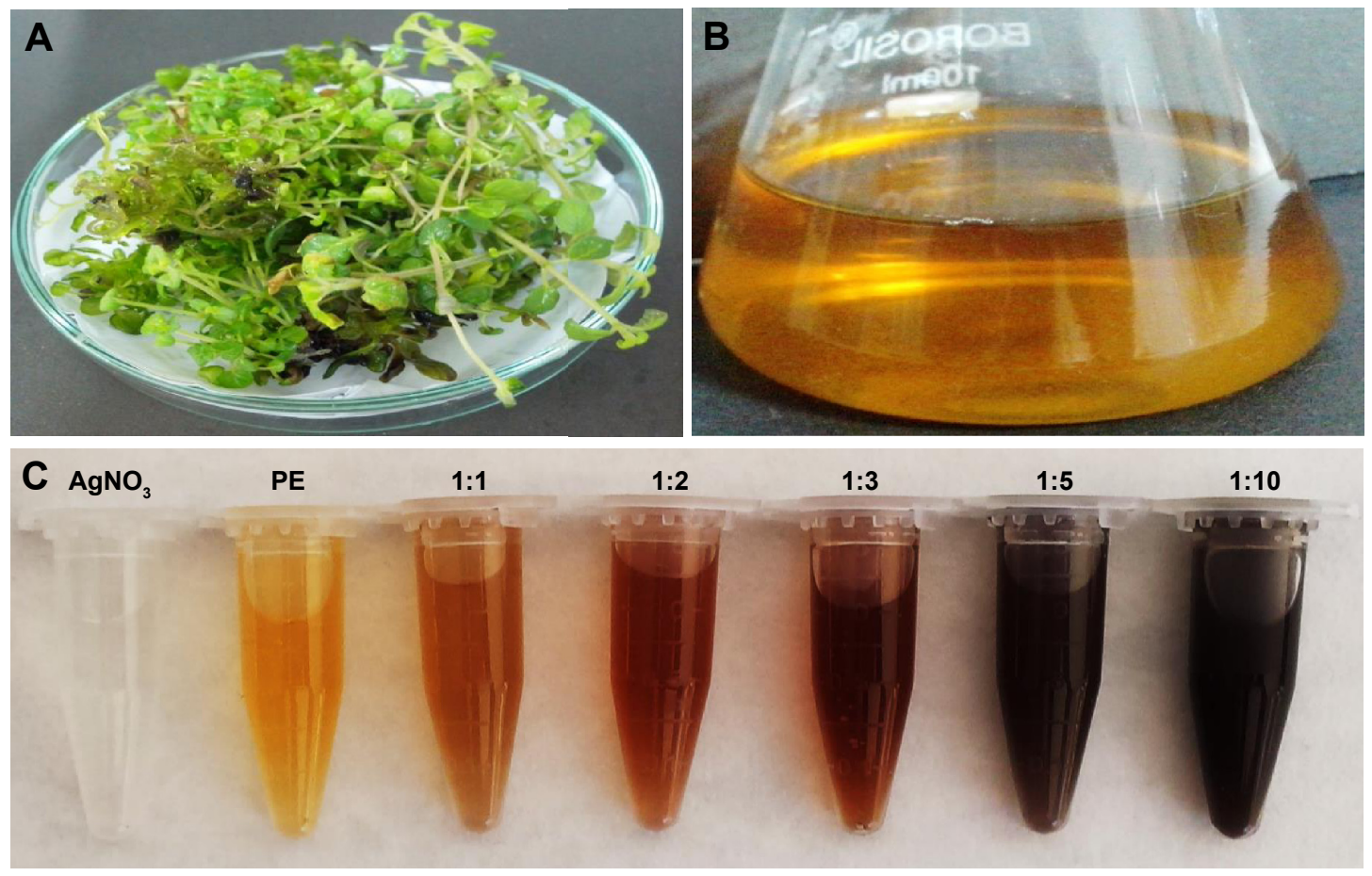

Figure I In vitro-derived plantlets of Phlomis bracteosa, its aqueous extract, and biosynthesis of AgNPs.

Notes: (A) In vitro propagated plantlets obtained from MS0 medium supplemented with $2.0 \mathrm{mg} / \mathrm{L}$ IBA. (B) Aqueous extract of $10 \mathrm{~g} / \mathrm{I} 00 \mathrm{~mL}$ of in vitro propagated plantlets. (C) Plantlets extract/AgNO $(\mathrm{v} / \mathrm{v})$ reaction mixtures in different ratios.

Abbreviations: AgNPs, silver nanoparticles; MSO, Murashige and Skoog basal medium; IBA, indole-3-butyric acid; PE, plant extract. 
placed in $100 \mathrm{~mL}$ distilled water and boiled for 15-20 minutes. The extract thus formed was cooled down to room temperature, filtered through a filter paper, and the volume of the filtrates were adjusted to $100 \mathrm{~mL}$ with distilled water (Figure 1B) and stored at $4^{\circ} \mathrm{C}$ for further use.

\section{Content determination}

Total phenolic content (TPC) was determined using FolinCiocalteu's reagent according to the method described by Velioglu et al. ${ }^{27}$ Absorbance was measured at $725 \mathrm{~nm}$ using UV/Vis HALO DB-20 spectrophotometer (Dynamical Ltd, Victoria, Australia). The calibration curve $(0-50 \mu \mathrm{g} / \mathrm{mL}$, $R^{2}=0.968$ ) was plotted using gallic acid as standard. All determinations were performed in triplicate, and the TPC was expressed as $\mathrm{mg} / \mathrm{g}$ gallic acid equivalents of dry weight (DW). Total flavonoid content (TFC) was determined using aluminum chloride colorimetric method as described by Chang et al. ${ }^{28}$ Absorbance of the reaction mixtures was measured at $415 \mathrm{~nm}$ by using UV/Vis HALO DB-20 spectrophotometer. The calibration curve $\left(0-40 \mu \mathrm{g} / \mathrm{mL}, R^{2}=0.998\right)$ was plotted using Quercetin as standard. The TFC was expressed as Quercetin equivalents/g of DW.

\section{Biomimetic synthesis of AgNPs}

Aqueous extract of in vitro propagated plantlets of $P$. bracteosa was mixed with silver nitrate solution $\left(\mathrm{AgNO}_{3}\right.$; $1 \mathrm{mM})$ in different ratios $(1: 1,1: 2,1: 3,1: 5$, and $1: 10 \mathrm{v} / \mathrm{v})$ to find out the appropriate concentrations of $\mathrm{AgNO}_{3}$ for optimal AgNPs biosynthesis. Briefly, $100 \mu \mathrm{L}$ of extract was mixed with $100 \mu \mathrm{L}$ of $\mathrm{AgNO}_{3}(1: 1$ ratio), and the subsequent mixtures were prepared by increasing $\mathrm{AgNO}_{3}$ volume up to $1,000 \mu \mathrm{L}$. These mixtures were prepared in $1.5 \mathrm{~mL}$ Eppendorf tubes and allowed to progress at room temperature for different time periods. The bioreduction of silver ions was observed by change in the color of the reaction mixtures during different time intervals $(0,10,20,30$ minutes, 1, 2, 6, and 12 hours).

\section{Characterization of AgNPs}

AgNPs biosynthesis was monitored by recording ultravioletvisible (UV-Vis) spectra $\left(\lambda_{300-750 \mathrm{~nm}}\right)$ as a function of time on a HALO DB-20 spectrophotometer. The reaction mixtures showing optimal biosynthesis of AgNPs were further ensued by pelleting and washing AgNPs to remove unreacted $\mathrm{AgNO}_{3}$ solution and plant extract. Briefly, $1 \mathrm{~mL}$ of each reaction mixture was centrifuged at 12,000 rpm for 10 minutes at room temperature. Supernatants were discarded and the AgNPs pellets were resuspended in $1 \mathrm{~mL}$ distilled water followed by centrifugation at $12,000 \mathrm{rpm}$ for 10 minutes. This process of washing was repeated three times, the resulting AgNPs were air dried to evaporate excessive liquid, and these were used for further characterization. Fourier-transform infrared spectroscopy (FTIR) spectrum of the synthesized AgNPs was recorded using Perkin-Elmer model in the transmittable mode at the range of 3,500-500 $\mathrm{cm}^{-1}$ in potassium bromide $(\mathrm{KBr})$ pellets to find out the possible functional groups involved in the reduction and stabilization of AgNPs.

The crystalline structure of the synthesized AgNPs was investigated by X-ray diffraction (XRD). Powdered sample was used, and the diffraction pattern was recorded in the scanning mode on a Shimadzu-Model XRD 6000 operated at $40 \mathrm{kV}$ with a current of $30 \mathrm{~mA}$ and $\mathrm{Cu} / \mathrm{K} \alpha$ radiation in the range of $20^{\circ}-70^{\circ}$ in $2 \theta$ angles. The average particle size of the synthesized AgNPs was calculated by using the DebyeScherrer equation. ${ }^{29}$

$$
D=\frac{k \lambda}{\beta \cos \theta}
$$

where $k=$ shape factor $(0.94) ; \lambda=\mathrm{X}$-ray wavelength ( $\lambda=1.5418 \AA) ; \beta=$ full width at half maximum (FWHM) in radians; and $\theta=$ Bragg's angle.

The morphology of synthesized AgNPs was observed by scanning electron microscopy (SEM) using the SIGMA model (MIRA3 TESCAN) operated at an accelerating voltage of $10 \mathrm{kV}$. The sample was prepared on a silica-coated copper grid by simply dropping a very small amount of the AgNPs on the grid. The film was then allowed to dry under a mercury lamp for 5 minutes, following which SEM images were collected at different magnifications. For elemental analysis, energy dispersive X-ray analysis (EDX) analysis was performed using the EDX-detector attached with SEM.

\section{Antimicrobial activities of AgNPs against multiple drug-resistant bacterial strains} Escherichia coli (ATCC-15224), Staphylococcus aureus (ATCC-6538), and Klebsiella pneumoniae (ATCC-4619) bacterial strains were obtained from the American Type Culture Collection (ATCC), Manassas, VA, USA. In vitro antibacterial activity was carried out with synthesized AgNPs by well diffusion method. In brief, the dried AgNPs were weighed $(10 \mu \mathrm{g} / \mathrm{mL})$ and dissolved in sterile distilled water and used immediately. The inoculums of highly multiple drug-resistant bacterial strains were prepared by growing a single colony for 24 hours in nutrient broth. The nutrient agar plates were swabbed with bacterial strains broth, and 
$20 \mu \mathrm{L}$ of each synthesized-AgNPs $(10 \mu \mathrm{g} / \mathrm{mL}), 1 \mathrm{mM}$ $\mathrm{AgNO}_{3}$ (positive control), commercial antibiotic as standard (Ampiclox, $10 \mu \mathrm{g} / \mathrm{mL}$ ), and plant extract (PE) (negative control) were added in wells. These sample-loaded plates were incubated at $37^{\circ} \mathrm{C}$ for 48 hours in an incubator, and the zone of inhibition ( $\mathrm{mm}$ ) was measured. Data were collected from three independent experiments for each strain and repeated thrice.

\section{Statistical analysis}

All experiments were performed in triplicate. Standard errors $( \pm)$ and mean values of various treatments were determined by analysis of variance. Significant difference was separated using Duncan's multiple range test, set at $P<0.05$. $^{30}$

\section{Results and discussion \\ Direct shoot regeneration}

The rapid advancement in the field of plant biotechnology is primarily due to the development of proficient regeneration protocols for medicinally important endemic and endangered plant species. Direct shoot regeneration from primary explant tissues is more attractive and economical than passing through an intermediate callus phase. ${ }^{31}$ For direct shoot organogenesis, $1-2 \mathrm{~cm}$ of stem explants from in vitro-germinated plantlets were inoculated on MS0 media, supplemented with various concentrations $(0.5-5.0 \mathrm{mg} / \mathrm{L})$

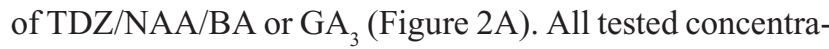
tions of PGRs supported direct shoot regeneration except $0.5 \mathrm{mg} / \mathrm{L}$ concentration of BA, NAA, or GA (Table 2). The highest shoot formation frequency $(78 \% \pm 4.09 \%)$ (Figure 2B) was observed in response to $2.0 \mathrm{mg} / \mathrm{L} \mathrm{TDZ}$, followed by $2.0 \mathrm{mg} / \mathrm{L}$ of NAA $(72 \% \pm 4.11 \%)$. The number of shoots/explants $(32.0 \% \pm 0.29 \%)$ was significantly higher in response to $2.0 \mathrm{mg} / \mathrm{L} \mathrm{TDZ}$ than all other tested treatments of PGRs (Figure 2C). Similar significant effects of TDZ were previously reported on shoot multiplication of Balanites aegyptiaca and Dalbergia sisso. ${ }^{32,33}$ The highest shoot length $(5.4 \pm 0.43 \mathrm{~cm})$ was found in response to $2.0 \mathrm{mg} / \mathrm{L}$

Table 2 Effects of different PGR treatments on shoot formation frequency, mean shoot length, and number of shoots per explant in Phlomis bracteosa

\begin{tabular}{|c|c|c|c|c|}
\hline \multicolumn{5}{|c|}{ Shoot organogenesis } \\
\hline $\begin{array}{l}\text { Serial } \\
\text { number }\end{array}$ & PGRs treatments (mg/L) & $\begin{array}{l}\text { Shoot formation (\%) } \\
\text { (mean } \pm \text { SD) }\end{array}$ & $\begin{array}{l}\text { Mean shoot length }(\mathrm{cm}) \\
(\text { mean } \pm \text { SD) }\end{array}$ & $\begin{array}{l}\text { Number of shoots/ } \\
\text { explant (mean } \pm \text { SD) }\end{array}$ \\
\hline $\mathrm{I}$ & TDZ 0.5 & $10 \pm 1.15$ & $1.3 \pm 0.12$ & $5 \pm 0.11$ \\
\hline 2 & TDZ I.0 & $28 \pm 2.02$ & $1.5 \pm 0.14$ & $\mathrm{II} \pm 0.23$ \\
\hline 3 & TDZ 2.0 & $78 \pm 4.09$ & $5.2 \pm 0.69$ & $32 \pm 0.29$ \\
\hline 4 & TDZ 3.0 & $70 \pm 3.97$ & $2.4 \pm 0.33$ & $27 \pm 0.26$ \\
\hline 5 & TDZ 4.0 & $35 \pm 2.01$ & $1.7 \pm 0.22$ & $10 \pm 0.09$ \\
\hline 6 & TDZ 5.0 & $22 \pm 1.82$ & $1.2 \pm 0.09$ & $9 \pm 0.41$ \\
\hline 7 & NAA 0.5 & - & - & - \\
\hline 8 & NAA 1.0 & $5 I \pm 2.31$ & $2.3 \pm 0.18$ & $18 \pm 0.38$ \\
\hline 9 & NAA 2.0 & $72 \pm 4.11$ & $5.3 \pm 0.21$ & $2 I \pm 0.18$ \\
\hline 10 & NAA 3.0 & $62 \pm 3.56$ & $3.5 \pm 0.41$ & $24 \pm 0.19$ \\
\hline II & NAA 4.0 & $44 \pm 2.02$ & $3.2 \pm 0.32$ & $18 \pm 0.22$ \\
\hline 12 & NAA 5.0 & $33 \pm 2.01$ & $2.1 \pm 0.22$ & $13 \pm 0.15$ \\
\hline 13 & BA 0.5 & - & - & - \\
\hline 14 & BA I.0 & $23 \pm 1.23$ & $1.9 \pm 0.08$ & $|8 \pm 0.1|$ \\
\hline 15 & BA 2.0 & $66 \pm 2.45$ & $5.4 \pm 0.43$ & $29 \pm 1.21$ \\
\hline 16 & BA 3.0 & $55 \pm 2.65$ & $2.9 \pm 0.27$ & $13 \pm 0.37$ \\
\hline 17 & BA 4.0 & $24 \pm 1.09$ & $2 . I \pm 0.2 I$ & $7 \pm 0.26$ \\
\hline 18 & BA 5.0 & $22 \pm 0.79$ & $1.6 \pm 0.11$ & $4 \pm 0.03$ \\
\hline 19 & $\mathrm{GA}_{3} 0.5$ & - & - & - \\
\hline 20 & $\mathrm{GA}_{3} \mathrm{I} .0$ & $12 \pm 0.78$ & $\mid .3 \pm 0.2 \mathrm{I}$ & $3 \pm 0.04$ \\
\hline 21 & $\mathrm{GA}_{3} 2.0$ & $22 \pm 1.08$ & $1.7 \pm 0.17$ & $7 \pm 0.12$ \\
\hline 22 & $\mathrm{GA}_{3} 3.0$ & $38 \pm 1.78$ & $2.1 \pm 0.25$ & $11 \pm 0.22$ \\
\hline 23 & $\mathrm{GA}_{3} 4.0$ & $30 \pm 2.08$ & $1.6 \pm 0.09$ & $5 \pm 0.08$ \\
\hline 24 & $\mathrm{GA}_{3} 5.0$ & $18 \pm 1.06$ & $I . I \pm 0.06$ & $2 \pm 0.05$ \\
\hline 25 & MSO & - & - & - \\
\hline
\end{tabular}

Note: Values mean $\pm S D$ indicate the replicates of three experiments.

Abbreviations: PGR, plant growth regulator; SD, standard deviation; TDZ, thidiazuron; NAA, $\alpha$ naphthalene acetic acid; BA, 6-benzylaminopurine; GA, gibberellic acid; MSO, Murashige and Skoog basal medium. 

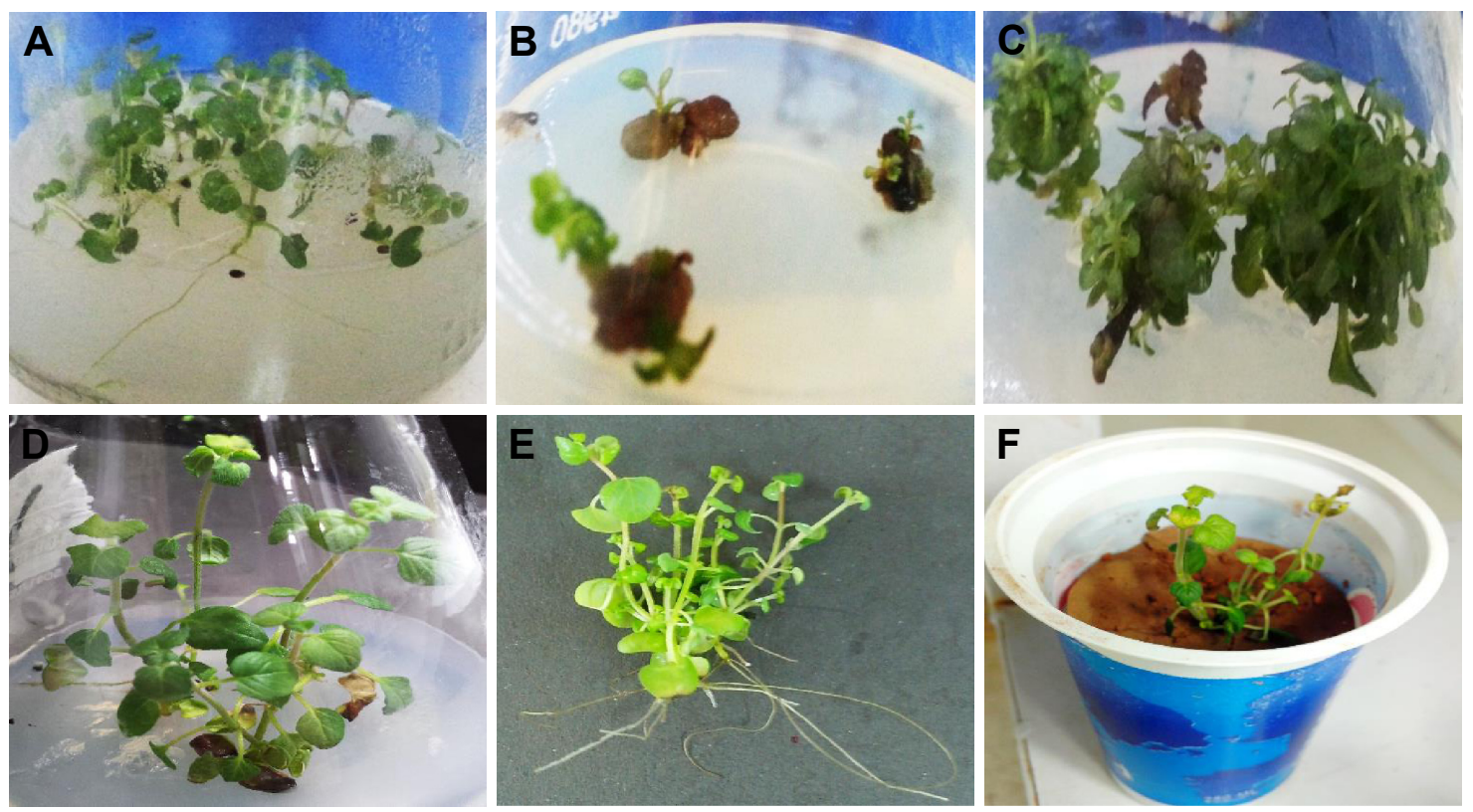

Figure 2 In vitro micropropagation of Phlomis bracteosa from stem explant.

Notes: (A) Seeds germinated on PGRs free MSO medium. (B) Shoot induction form stem explant after I week of culture. (C) Shoot multiplication after 2 weeks of culture. (D) Regenerated shoots shifted to rooting media after 4 weeks of culture. (E) Shoots with well-developed roots after 4 weeks of shifting to rooting media. (F) Acclimatization of shoots in sterilized organic manure, clay soil, and sand $(I: I: I)$.

Abbreviations: PGR, plant growth regulator; MSO, Murashige and Skoog basal medium.

BA, followed by $2.0 \mathrm{mg} / \mathrm{L}$ treatment of NAA $(5.3 \pm 0.21$ $\mathrm{cm})$ (Table 2). Similar results were also reported in previous studies in which BA and NAA strongly promoted shoot multiplication and shoot length in Curcuma zedoaria and Curcuma longa. ${ }^{34,35}$ In general, by increasing concentrations of PGRs from 0.5 to $2.0 \mathrm{mg} / \mathrm{L}$, the responding frequency of shoot induction, average shoot length, and number of shoots/explants increases. But, increasing the concentration of either BA, TDZ, NAA, or $\mathrm{GA}_{3}>3.0 \mathrm{mg} / \mathrm{L}$ in the MS0 media resulted in decrease (Figure 2D) of all kinds of morphogenic responses. ${ }^{33-35} \mathrm{TDZ}(2.0 \mathrm{mg} / \mathrm{L})$ was found to be highly efficient for direct shoot organogenesis in P. bracteosa and also resulted in higher number of shoots/explants than all other treatments of PGRs. TDZ is a comparatively better bioregulator of plant morphogenesis, and this might be due to its dual activity (auxins as well as cytokinins). The superiority of TDZ for direct shoot regeneration over other PGRs has been reported in several other plant species. ${ }^{36,37}$

\section{Root induction and acclimatization}

The success of in vitro micropropagation depends on efficient root induction frequency and survival of regenerated plantlets under field conditions. ${ }^{38}$ In vitro regenerated shoots (3-4 cm) with four to five nodal leaves were excised and inoculated individually on MS0 medium supplemented with various concentrations $(0.5-5.0 \mathrm{mg} / \mathrm{L})$ of IBA and IAA alone. All tested concentrations of IBA were found to be more effective in inducing root formation in regenerated shoots than IAA (Table 1). Shoot transferred to MS0 medium without any PGRs did not show any root induction. The highest root induction frequency $(86 \% \pm 4.457 \%)$, mean number of roots/ explants $(0.9 \pm 0.336)$, and average root length $(4.3 \pm 0.466 \mathrm{~cm})$ were attained after 5 weeks, when regenerated shoots were inoculated on to MS0 medium containing $2.0 \mathrm{mg} / \mathrm{L} \mathrm{IBA}$ (Figure 2E). Generally, IBA is considered as more effective PGR for root induction in regenerated shoots than all other auxins. Similar efficacy of IBA on root induction frequency was also reported in many other plant species. ${ }^{39,40}$ Well-rooted plantlets were shifted to plastic cups containing organic manure, clay soil, and sand (1:1:1) for hardening and were successfully established (72.3\% survival rate) under greenhouse conditions (Figure 2F). After 3 weeks, regenerated plantlets were transferred into earthen pot containing garden soil and finally acclimatized in the field with $68 \%$ survival rate.

\section{TPC and TFC}

P. bracteosa, a high-value medicinal plant, is known to be a rich source of diverse bioactive compounds (phenolics, flavonoids, terpenoids, saponins, and tannins) that might play a significant role in the reduction of $\mathrm{Ag}^{+}$to AgNPs. ${ }^{15,19}$ Phytochemical analysis of aqueous extract of in vitro-propagated plantlets of $P$. bracteosa revealed high levels of TPC (8.13 $\mathrm{mg} / \mathrm{g} \mathrm{DW})$ and TFC (4.13 mg/g DW). These phytochemicals may be responsible for the reduction, capping, and 
stabilization of AgNPs. ${ }^{10,41}$ Phenolics, flavonoids, reducing sugars, and proteins that are present in almost all medicinal plants have been reported to act as bioreductants of metallic ions in aqueous medium. ${ }^{1,11}$

\section{Biomimetic synthesis of AgNPs}

Formation of AgNPs in aqueous extracts can be monitored visually by color change from yellowish brown to dark brown. ${ }^{3,6}$ In our initial experiments, $100 \mu \mathrm{L}$ of aqueous extract of $P$. bracteos $a$ was mixed with $100 \mu \mathrm{L}$ of $1 \mathrm{mM}$ $\mathrm{AgNO}_{3}$ solution in different v/v ratios $(1: 1,1: 2,1: 3,1: 5$, 1:10; extract $/ \mathrm{AgNO}_{3}$ ) and kept at room temperature for 12 hours to observe color changes. Reaction mixtures started turning brown as they were mixed, with the color becoming darker with the passage of time. However, no color change was observed with the aqueous extract or $\mathrm{AgNO}_{3}$ solution alone under the same conditions (Figure 1C). The highest color intensity was observed in reaction mixtures of 1:5 and $1: 10 \mathrm{v} / \mathrm{v}$ ratios, indicating more reduction of $\mathrm{Ag}^{+}$to $\mathrm{AgNPs}$ as compared to other reaction mixtures. This showed that higher concentrations of $\mathrm{AgNO}_{3}$ solution sped up the biosynthesis of AgNPs, which is in agreement with a previous study involving Agrimoniae herba extract as reducing agent. ${ }^{42}$ The change in color is the primary indication of formation of AgNPs, and this is due to the strong absorption of visible light resulting in excitation of surface plasmon resonance in AgNPs. ${ }^{6,42}$

\section{UV-Vis spectroscopy of synthesized AgNPs}

The UV-Vis spectroscopy is one of the vital techniques used for analyzing AgNPs formation and stability in aqueous solution. It is reported in the literature that the AgNPs exhibit characteristic surface plasmon resonance peak in the range of 400-460 nm wavelength. ${ }^{43,44}$ As shown in Figure 3,

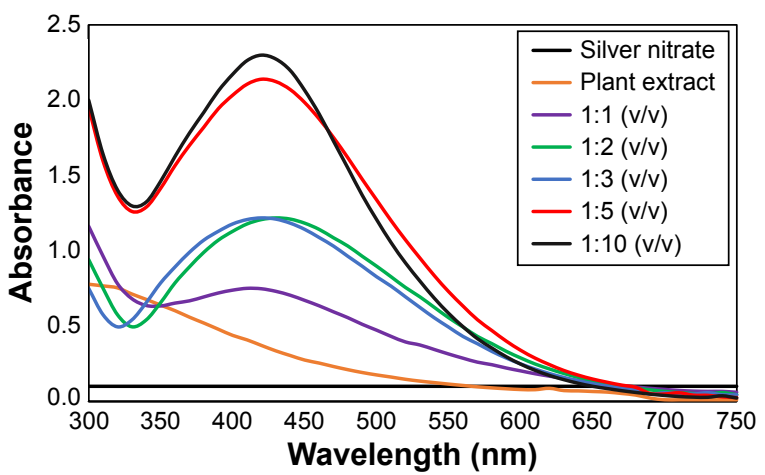

Figure 3 UV-Vis spectrum of AgNPs.

Note: Plantlets extract $/ \mathrm{AgNO}_{3}(\mathrm{v} / \mathrm{v})$ reaction mixtures in different ratios after 12 hours of incubation.

Abbreviations: UV-Vis, ultraviolet-visible; AgNPs, silver nanoparticles.
Table 3 Synthetic formulation and the UV-Vis wavelength peaks of green synthesized AgNPs

\begin{tabular}{llll}
\hline $\begin{array}{l}\text { Plant extract } \\
(10 \mathrm{~g} / 100 \mathrm{~mL})+\end{array}$ & $\begin{array}{l}\text { Plant extract/ } \\
\mathbf{A g N O}_{3} \text { ratios }\end{array}$ & $\begin{array}{l}\text { Wavelength } \\
(\mathbf{n m})\end{array}$ & Absorbance \\
$\mathrm{AgNO}_{3}(\mathrm{I} \mathrm{mM})$ & $(\mathrm{v} / \mathrm{v})$ & & \\
\hline $100+1,000 \mu \mathrm{L}$ & $\mathrm{I}: 10$ & 420 & 2.299 \\
$100+500 \mu \mathrm{L}$ & $1: 5$ & 423 & 2.139 \\
$100+300 \mu \mathrm{L}$ & $1: 3$ & 428 & 1.218 \\
$100+200 \mu \mathrm{L}$ & $1: 2$ & 429 & 1.196 \\
$100+100 \mu \mathrm{L}$ & $\mathrm{I}: 1$ & - & - \\
\hline
\end{tabular}

Abbreviations: UV-Vis, ultraviolet-visible; AgNPs, silver nanoparticles.

the in vitro propagated plantlets extract mixed with $\mathrm{AgNO}_{3}$ solution in different ratios, showed characteristic surface plasmon resonance between 420 and $429 \mathrm{~nm}$, indicating the presence of AgNPs in the solution. However, the 1:1 ratio reaction mixtures did not show any characteristic peak of AgNPs (Table 3). Highest absorbance with comparatively narrow peaks was observed when extract was mixed with $\mathrm{AgNO}_{3}$ solution in a 1:10 ratio, indicating higher yield of nanoparticles. The increase in absorbance intensity is due to increasing number of AgNPs formed as a result of reduction of silver ions. ${ }^{11,29}$ It is well known that the absorbance intensity mainly depends upon the size and shape of AgNPs, and, in general, absorbance peaks decrease as the size of the nanoparticles increases. ${ }^{44}$

\section{Growth kinetics of AgNPs synthesis}

To find out the reduction time of silver ions in reaction mixtures, we investigated the absorbance intensities and wavelength peaks of reaction mixtures at different time intervals (10 minutes-12 hours) by using UV-Vis spectrophotometer. As shown in Figure 4, an expansion of reaction time was accompanied with an obvious increase in the absorbance intensity before 4 hours in 1:2, 1:3, and 1:5 ratio mixtures, but no significant enhancement was found after 4 hours.

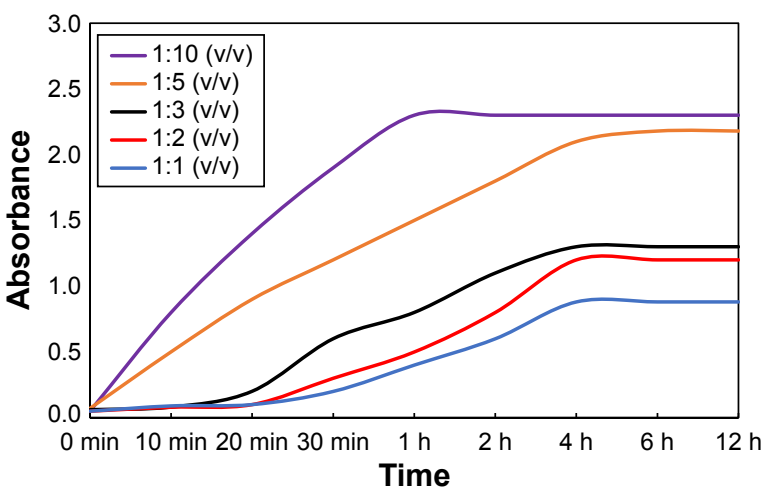

Figure $4 \mathrm{UV}-\mathrm{Vis}$ absorbance profiles of AgNPs synthesis as a function of time. Note: Plantlets extract $/ \mathrm{AgNO}_{3}(\mathrm{v} / \mathrm{v})$ reaction mixtures in different ratios. Abbreviations: UV-Vis, ultraviolet-visible; AgNPs, silver nanoparticles; min, minutes; h, hours. 
This showed that the reduction of silver ions in these reaction mixtures was completed within 4 hours and that there was no further increase in absorption till 12 hours, while in the case of 1:10 ratio mixture, reduction of silver ions was completed within 1 hour, resulting in high yield of nanoparticles within short time. This might be due to higher concentration of $\mathrm{AgNO}_{3}$ solution, resulting in rapid biosynthesis of AgNPs by speeding up the reduction of silver ions. Similar results were also reported in synthesis of AgNPs using extract of A. herba and Chrysanthemum indicum. ${ }^{29,42}$ Moreover, the stability of the synthesized AgNPs was examined by keeping the reaction mixture (1:10 ratio) at room temperature for 4 months, and it was found that the reaction mixture showed peak at the same wavelength with similar absorption intensity which confirmed the stability of synthesized AgNPs. Since, the reaction mixture with 1:10 ratio showed high absorption peak at $420 \mathrm{~nm}$ with comparatively narrow peak and complete reduction in lesser time period, we further characterized AgNPs formed only in this reaction mixture.

\section{FTIR analysis}

The FTIR analysis was carried out to determine the possible biomolecules involved in the reduction, capping, and stabilization of synthesized AgNPs. FTIR spectrum (Figure 5) of AgNPs showed strong absorption peaks at approximately 3,728.17, 3,702.66, 3,626.78, 3,695.42, 3,249.07, 2,882.08,
2,772.99, 1,717.21, 1,675.53, 1,596.08, 1,096.44, 1,065.14, $856.36,823.36$, and $688.37 \mathrm{~cm}^{-1}$. The observed peaks were compared with standard values to identify the functional groups. The absorption peaks in the region of 3,728.17$3,249.07 \mathrm{~cm}^{-1}$ were assigned to strong - $\mathrm{OH}$ stretching in alcohols and phenolic compounds. ${ }^{1}$ The intense bands in the region of 2,882.08-2,772.99 $\mathrm{cm}^{-1}$ corresponded to $-\mathrm{C}=\mathrm{O}$ and $-\mathrm{C}-\mathrm{H}$ stretching of aldehyde functional groups, while the broad band at $1,717.21 \mathrm{~cm}^{-1}$ may have been be due to $-\mathrm{OH}$ stretching of carboxylic acids. ${ }^{6}$ The absorption band at $1,675.53$ and $1,596.08 \mathrm{~cm}^{-1}$ corresponded to stretching of nitrile groups. ${ }^{45}$ The peak $\sim 856.36-823.36 \mathrm{~cm}^{-1}$ region represented the $-\mathrm{C}=\mathrm{C}-$ bending of the aromatic disubstituted compounds. ${ }^{42}$ The present data strongly indicated the involvement of polyphenols (phenolics and flavonoids), carboxylic acids, and aromatic and carbonyl compounds in reduction and capping of AgNPs. Our results are in good agreement with other reports available in the literature suggesting the involvement of aforementioned groups in biomimetic synthesis of AgNPs. ${ }^{42-44,46}$

\section{XRD analysis}

$\mathrm{XRD}$ analysis provides information about crystalline structure of the AgNPs. ${ }^{46}$ XRD spectrum (Figure 6) showed three diffraction peaks at $38.21^{\circ}, 46.95^{\circ}$, and $64.53^{\circ}$, attributed to 111,200 , and 220 lattice planes of the face-centered cubic

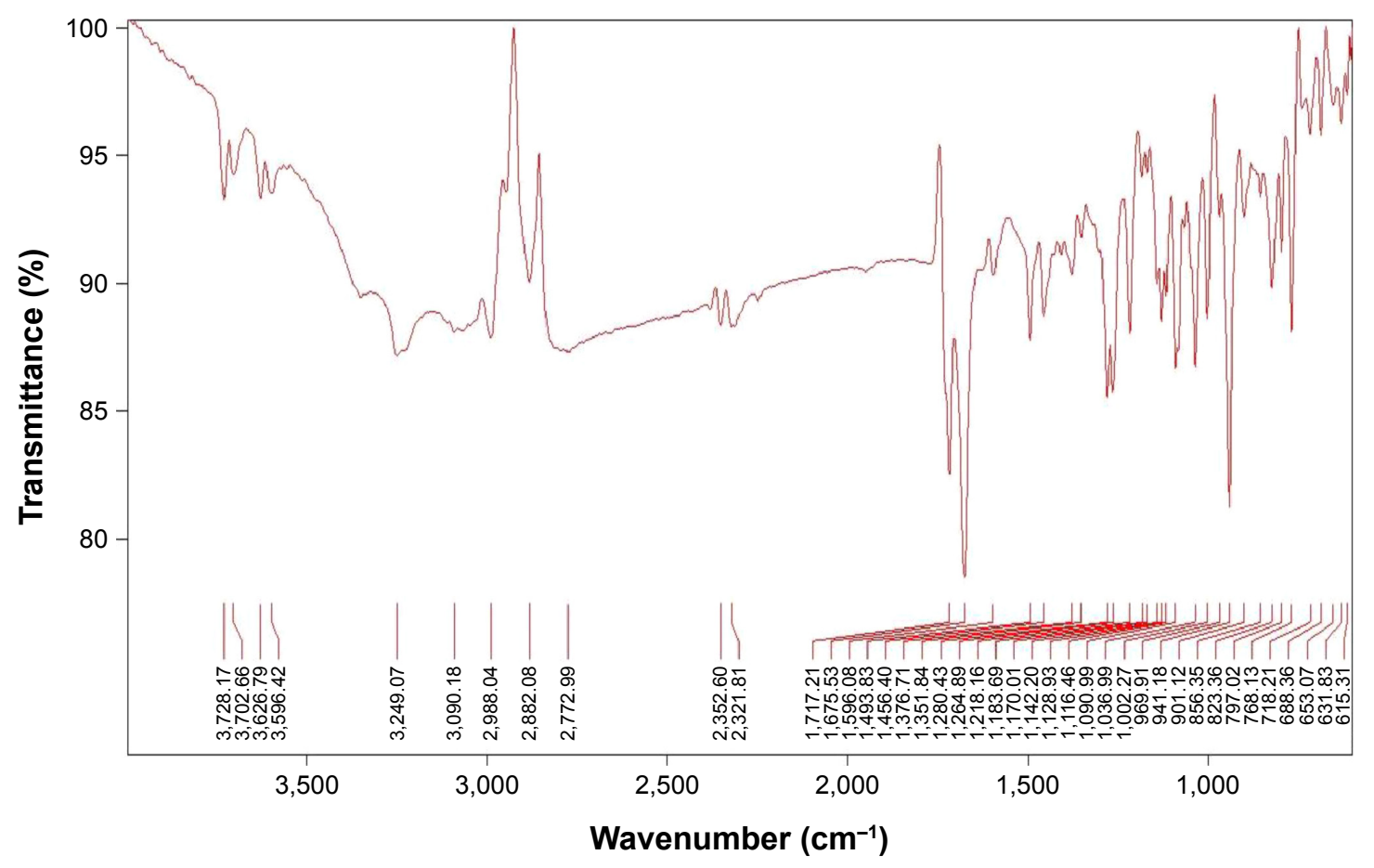

Figure 5 FTIR spectrum of synthesized AgNPs.

Abbreviations: FTIR, Fourier-transform infrared spectroscopy; AgNPs, silver nanoparticles. 


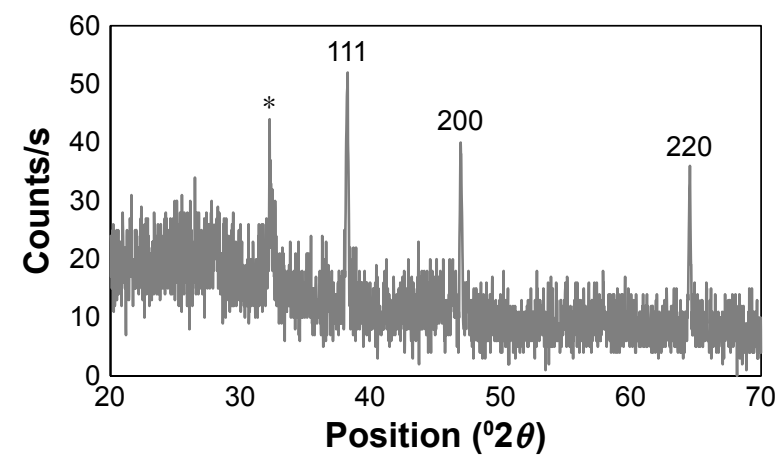

Figure 6 XRD pattern of synthesized AgNPs.

Note: *Indicates the unidentified peaks.

Abbreviations: XRD, X-ray diffraction; AgNPs, silver nanoparticles.

crystalline silver, respectively. ${ }^{42}$ Additionally, an unmapped peak was also observed at $32.23^{\circ}$ in the spectrum, indicating the presence of various phytochemicals on the surface of AgNPs, which are responsible for their capping. This peak is also apparent in many other reports in which the XRD pattern includes the relevant $2 \theta$ range. ${ }^{43}$ Debye-Scherrer equation was used to determine the average size of synthesized AgNPs by determining the FWHM of the Bragg's reflection corresponding to (111) crystalline plane of synthesized AgNPs. ${ }^{44}$ The average size was calculated to be $\sim 22.41 \mathrm{~nm}$, which is also in good agreement with the sizes calculated by SEM. The line broadening of the peaks is primarily attributed to the smaller size of AgNPs. ${ }^{43,47}$

\section{SEM and EDX analysis}

SEM analysis provided further insight into the size and morphology of synthesized AgNPs. ${ }^{48}$ Figure 7A showed that the AgNPs were spherical (bead-like) in shape and were well dispersed. Size calculation by Sigma Scan Pro software (Systat Software Inc., San Jose, CA, USA) attached with SEM showed that the AgNPs vary in the range of $20-25 \mathrm{~nm}$ in size, which is in good agreement with size calculated by XRD $(22.41 \mathrm{~nm})$. SEM image also showed that the large bioactive compounds were attached to the surfaces of small AgNPs, making them stable by preventing agglomeration. ${ }^{6,10,11}$ The presence of metallic silver in the synthesized AgNPs was further confirmed by the EDX analysis. The EDX spectrum (Figure 7B) showed strong peaks of metallic silver in the range of 3.0-4.0 keV. Metallic silver nanocrystal usually showed strong absorption spectra in the range of $2.5-4.0 \mathrm{keV}$, and similar results were also reported earlier. ${ }^{44,47}$ In addition to this, two peaks at approximately 2.5 and $8.1 \mathrm{keV}$ were attributed to the glass silica $(\mathrm{Si})$ and copper $(\mathrm{Cu})$, which were used for preparation of sample for SEM analysis. ${ }^{49}$

\section{Putative mechanism involved in biomimetic synthesis of AgNPs}

The putative mechanism involved in biomimetic synthesis of AgNPs by plant active compounds is still largely unmapped. ${ }^{1}$ Phytochemical analysis of aqueous extract of in vitro-propagated plantlet of $P$. bracteosa revealed that it is rich in phenolics $(8.02 \mathrm{mg} / \mathrm{g} \mathrm{DW})$ and flavonoids $(4.13 \mathrm{mg} / \mathrm{g}$ DW) content. Similar to our results, high flavonoid content $(1.52 / 100 \mathrm{~g} \mathrm{DW})$ was reported in wild plant extract of this species, which had 5,7,2-trihydroxyflavone $(9.0 \mathrm{mg} / 100 \mathrm{~g} \mathrm{DW})$ as a principal flavonoid (studied by by Ullah et $\mathrm{al}^{50}$ ). FTIR analysis also revealed that the
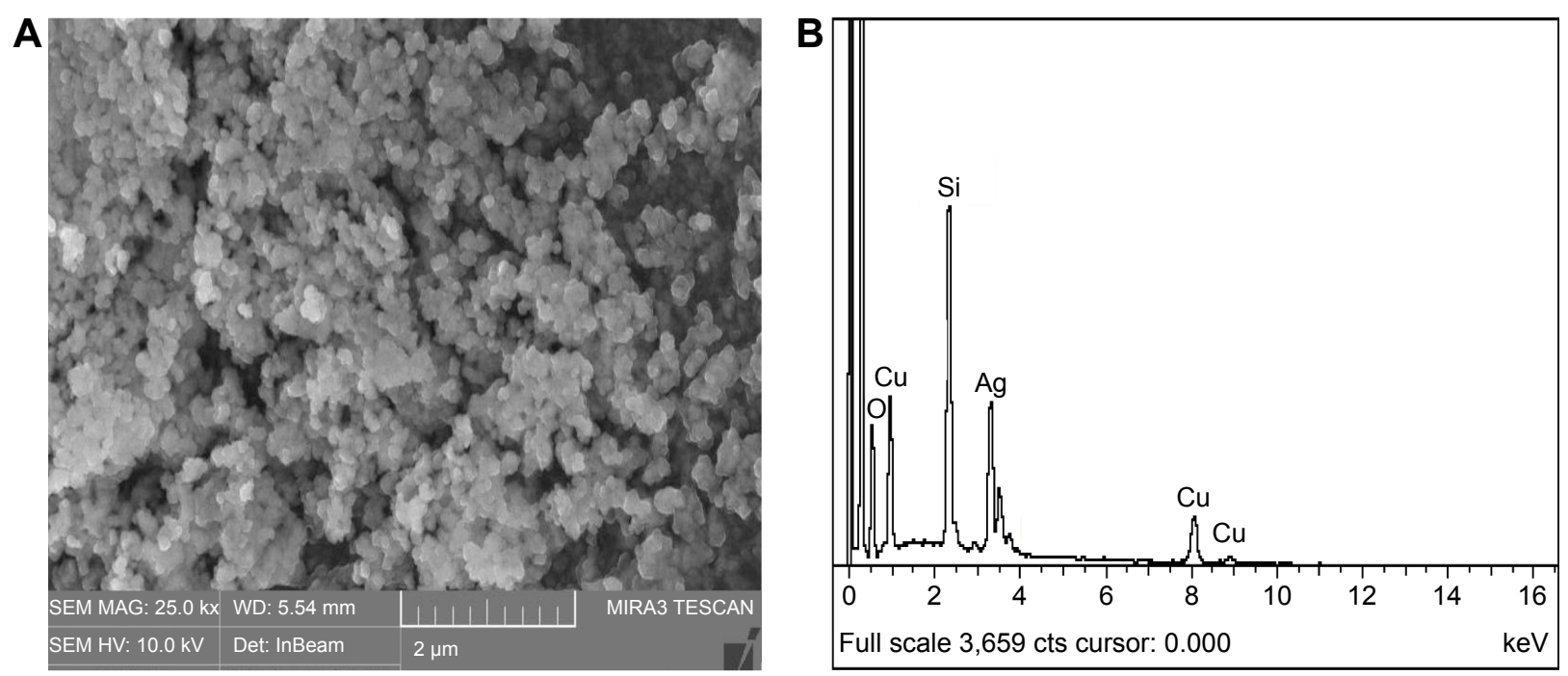

Figure 7 (A) SEM image of synthesized AgNPs. (B) EDX spectrum of synthesized AgNPs.

Abbreviations: SEM, scanning electron microscope; AgNPs, silver nanoparticles; EDX, energy dispersive $\mathrm{X}$-ray analysis. 
polyphenols, flavonoids, and aromatic compounds are chiefly responsible for reduction and stabilization of AgNPs. We, therefore, hypothesize the mechanism of reduction of silver ions by using 5,7,2-trihydroxyflavone through a redox reaction (Figure $8 \mathrm{~A}$ ). The presence of silver ion in plant extract first forms an intermediate silver complex with 5,7,2-trihydroxyflavone and then oxidizes it into keto form with the release of free electrons and $\mathrm{Ag}^{+}$ions. These $\mathrm{Ag}^{+}$ ions then reduced to zero valent silver $\left(\mathrm{Ag}^{0}\right)$ in the presence of free electrons produced in the reduction process.
The byproducts produced during the reduction reaction are the nitrate ions and unreacted plant secondary metabolites, which are removed during washing of AgNPs. ${ }^{1,51}$ Figure 8B shows the possible capping mechanism of polyphenolic compounds. This interaction between the hydroxyl groups of 5,7,2-trihydroxyflavone with AgNPs is due to the negative zeta-potential value of $\mathrm{Ag}^{0}$ in its pure form. ${ }^{52}$ This proposed mechanism of the reduction and stabilization of biomimetic synthesis of AgNPs biosynthesis is in agreement with previous reports..$^{1,52-54}$

A<smiles>N#[14C]c1cc(O)c2c(=O)cc(-c3ccccc3O)oc2c1</smiles>

5,7,2-Trihydroxyflavone
(enol form)<smiles></smiles>

Intermediate complex

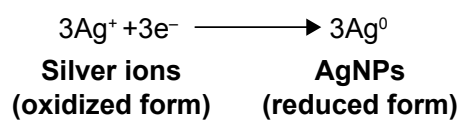<smiles>C[C@H]1c2c(oc(C3=CCC=CC3=O)cc2=O)CC(=O)[C@@H]1[18OH]</smiles>

Oxidized form

(keto form)

B

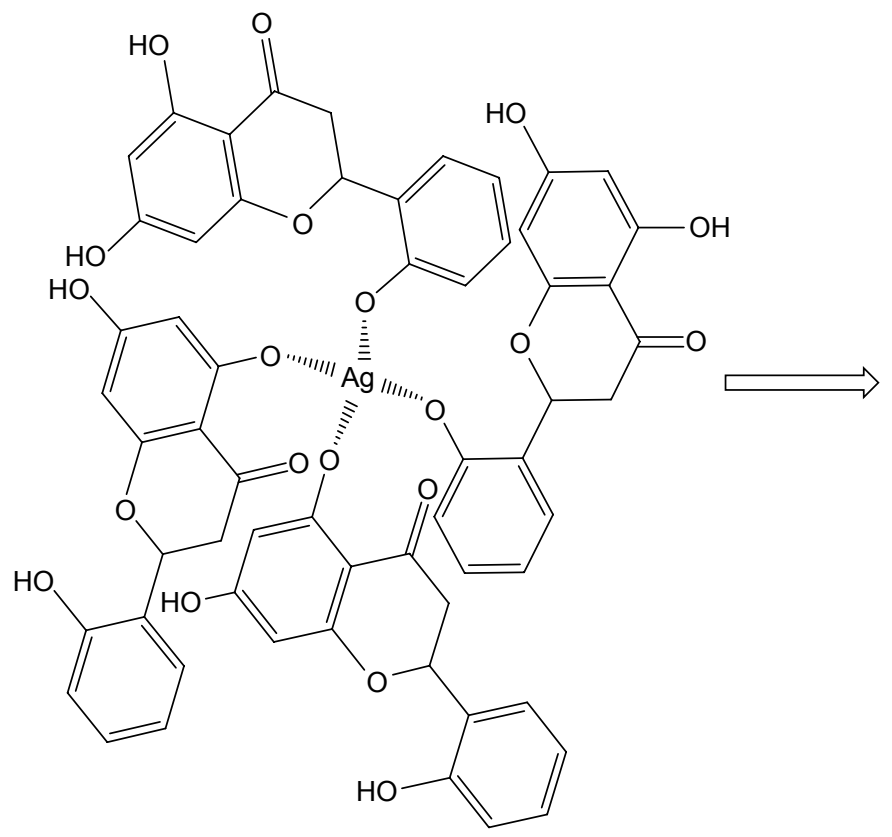

Capping of AgNPs by 5,7,2-trihydroxyflavone

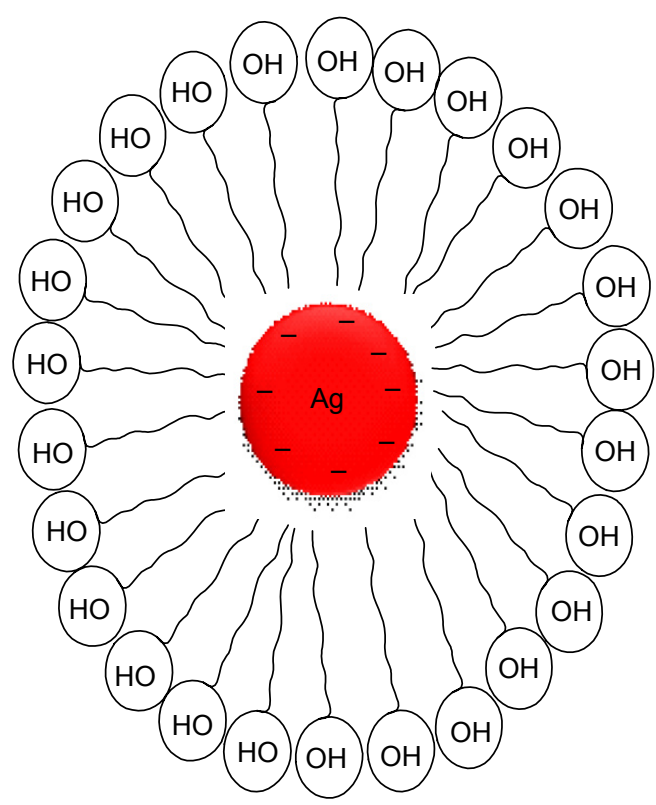

Stabilized AgNPs

Figure 8 Mechanistic scheme of biomimetic synthesis of AgNPs.

Notes: (A) Redox reaction showing mechanism of reduction of $\mathrm{Ag}^{+}$into $\mathrm{Ag}^{0}$ by using 5,7,2-trihydroxyflavone. (B) Capping and stabilization of $\mathrm{AgNPs}$ by hydroxyl groups of 5,7,2-trihydroxyflavone.

Abbreviation: AgNPs, silver nanoparticles. 

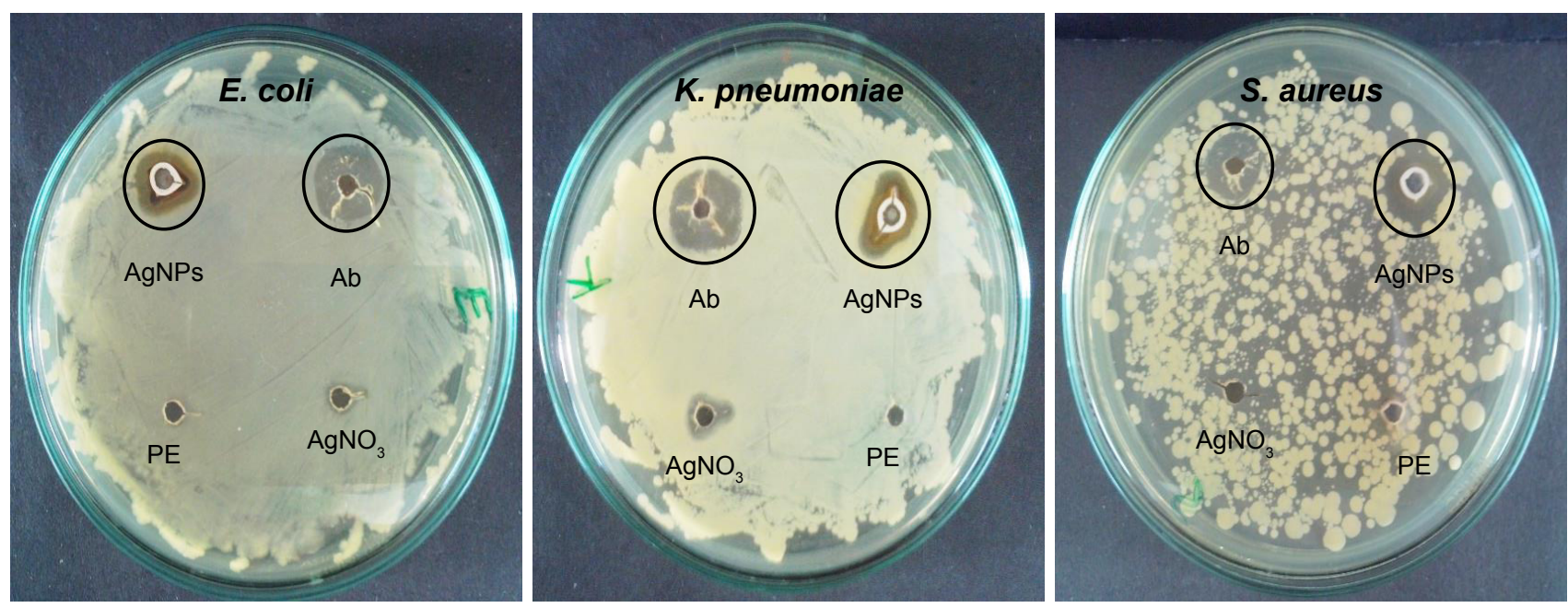

Figure 9 Antibacterial assay of AgNPs.

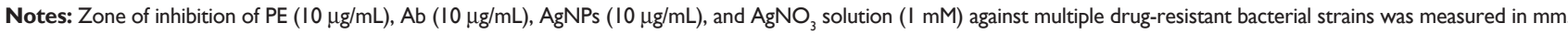
Abbreviations: E. coli, Escherichia coli; K. pneumoniae, Klebsiella pneumoniae; S. aureus, Staphylococcus aureus; AgNPs, silver nanoparticles; PE, plant extract; Ab, antibiotic.

\section{Antibacterial activities of AgNPs}

The antimicrobial efficacy of biosynthesized AgNPs was examined against three highly multiple drug resistant bacterial strains (E. coli, K. pneumoniae, and S. aureus) by using a standard antibiotic (Ampiclox, GlaxoSmithKline plc, London, UK), positive control ( $1 \mathrm{mM} \mathrm{AgNO}_{3}$ ) and negative control (PE). $\mathrm{AgNO}_{3}$ solution or $\mathrm{PE}$ alone showed minimal level of bactericidal activity in comparison to biosynthesized AgNPs (Figure 9). Biosynthesized AgNPs showed zone of inhibition $(\mathrm{mm})$ similar to the standard antibiotic (Table 4), suggesting their role as potent antimicrobial agents. Similar antibacterial activity was reported by AgNPs, greenly synthesized by alcoholic flower extract of Nyctanthes arbortristis ${ }^{45}$ and aqueous callus extract of Linum usitatissimum $L .{ }^{54}$ The mechanism behind the antibacterial activity of AgNPs is not yet fully explored. Probably, AgNPs exhibit bactericidal activity by interacting with bacterial cell wall, deactivating the cellular enzymes, and causing disruptions in plasma membrane permeability. This disruption may result in release of reactive oxygen species that can damage the DNA and proteins, eventually leading to the death of bacterial cells. ${ }^{6,55}$

\section{Conclusion}

In the present study, an efficient protocol has been developed for rapid, safe, and cost-effective biomimetic synthesis of AgNPs by exploiting in vitro regenerated plantlets of medicinally important endangered species, P. bracteosa. Small-sized AgNPs having face-centered cubic structure were synthesized within a short time at room temperature, without involving any noxious chemicals. These greensynthesized AgNPs presented promising antibacterial effects against multiple drug-resistant human pathogens. The present study has opened the new possible ways of utilizing in vitroderived cultures for biomimetic synthesis of antimicrobial AgNPs. These antimicrobial AgNPs capped with biologically active moieties can be used in many biomedical applications and also for the successful development of drug delivery in future.

Table 4 Antibacterial activity of greenly synthesized AgNPs against multiple drug-resistant bacterial strains

\begin{tabular}{|c|c|c|c|c|}
\hline \multirow[t]{2}{*}{ Organism } & \multicolumn{4}{|c|}{ Zone of inhibition $(\mathrm{mm})(20 \mu \mathrm{L} /$ well $)$} \\
\hline & $\begin{array}{l}\text { I } \mathrm{mM} \mathrm{AgNO}_{3} \\
(\text { mean } \pm \mathrm{SD})\end{array}$ & $\begin{array}{l}\text { Antibiotics }(10 \mu \mathrm{g} / \mathrm{mL}) \\
(\text { mean } \pm \mathrm{SD})\end{array}$ & $\begin{array}{l}\text { PE }(10 \mu g / m L) \\
(\text { mean } \pm S D)\end{array}$ & $\begin{array}{l}\text { AgNPs }(10 \mu g / m L) \\
(\text { mean } \pm \text { SD) }\end{array}$ \\
\hline Escherichia coli & $2.1 \pm 0.03$ & $15.1 \pm 1.03$ & - & $13.2 \pm 0.12$ \\
\hline Klebsiella pneumoniae & $3.2 \pm 0.09$ & $13.2 \pm 1.02$ & - & $10.3 \pm 0.11$ \\
\hline Staphylococcus aureus & $4.1 \pm 0.08$ & $10.1 \pm 0.90$ & - & $\mid I .1 \pm 0.10$ \\
\hline
\end{tabular}

Note: Values mean \pm SD indicate the replicates of three experiments.

Abbreviations: AgNPs, silver nanoparticles; SD, standard deviation; PE, plant extract. 


\section{Disclosure}

The authors report no conflicts of interest in this work.

\section{References}

1. Mittal AK, Bhaumik J, Kumar S, Banerjee UC. Biosynthesis of silver nanoparticles: elucidation of prospective mechanism and therapeutic potential. J Colloid Interface Sci. 2014;415:39-47.

2. Okafor F, Janen A, Kukhtareva T, Edwards V, Curley M. Green synthesis of silver nanoparticles, their characterization, application and antibacterial activity. Int J Environ Res Public Health. 2013;10(10): 5221-5238.

3. Song JY, Kim BS. Rapid biological synthesis of silver nanoparticles using plant leaf extracts. Bioprocess Biosyst Eng. 2009;32(1): 79-84.

4. Galletti AMR, Antonetti C, Marracci M, Piccinelli F, Tellini B. Novel microwave-synthesis of $\mathrm{Cu}$ nanoparticles in the absence of any stabilizing agent and their antibacterial and antistatic applications. Appl Surf Sci. 2013;280:610-618.

5. Kowshik M, Ashtaputre S, Kharrazi S, et al. Extracellular synthesis of silver nanoparticles by a silver-tolerant yeast strain MKY3. Nanotechnology. 2003;14(1):95.

6. Nazeruddin GM, Prasad NR, Waghmare SR, Garadkar KM, Mulla IS. Extracellular biosynthesis of silver nanoparticle using Azadirachta indica leaf extract and its anti-microbial activity. J Alloys Compd. 2014;583: 272-277.

7. Dorobantu LS, Fallone C, Noble AJ, et al. Toxicity of silver nanoparticles against bacteria, yeast, and algae. J Nanopart Res. 2015;17(4):1-13.

8. Marin S, Vlasceanu GM, Tiplea RE, et al. Applications and toxicity of silver nanoparticles: a recent review. Curr Top Med Chem. 2015;15(16): 1596-1604.

9. Rai M, Yadav A, Gade A. Silver nanoparticles as a new generation of antimicrobials. Biotechnol Adv. 2009;27(1):76-83.

10. Mukunthan K, Balaji S. Cashew apple juice (Anacardium occidentale L.) speeds up the synthesis of silver nanoparticles. Int J Green Nanotechnol. 2012;4(2):71-79.

11. Nabikhan A, Kandasamy K, Raj A, Alikunhi NM. Synthesis of antimicrobial silver nanoparticles by callus and leaf extracts from saltmarsh plant, Sesuvium portulacastrum L. Colloids Surf B Biointerfaces. 2010; 79(2):488-493.

12. Kharisov BI, Dias HR, Kharissova OV, Jiménez-Pérez VM, Perez BO, Flores BM. Iron-containing nanomaterials: synthesis, properties, and environmental applications. RSC Adv. 2012;2(25):9325-9358.

13. Hazrat A, Wahab M. Threatened native plants of Dir Kohistan valley, Khyber Pukhtunkhwa, Pakistan. FUUAST J Biol. 2011;1(1):35-38.

14. Ullah R, Hussain I, Ahmad S. Phytochemical and biological evaluation of Phlomis bracteosa: a review. Life Sci J. 2013;10(7s):1190-1192.

15. Joshi R, Pande V, Thakuri B. Antimicrobial activity of the essential oil of Phlomis bracteosa. Sci World. 2011;9(9):63-65.

16. Khan Au, Ullah R, Khan A, et al. Vasodilator effect of Phlomis bracteos $a$ constituents is mediated through dual endothelium-dependent and endothelium-independent pathways. Clin Exp Hypertens. 2012;34(2): $132-139$.

17. Ullah R, Al-Zeghayer YS, Haider S. Immunomodulatory potential of Phlomis bracteosa. Afr J Pharm Pharmacol. 2011;5(15):1811-1812.

18. Ullah R, Khader JA, AbdEIslam NM, Ayaz S, Hussain I, Ahmad S. Biological potential of Phlomis bracteosa. Life Sci J. 2013;10(1):3954-3957.

19. Hussain J, Farman UK Riaz U, et al. Evaluation of the Chemical Composition and Trace Elements Analysis of Nepeta suavis and Phlomis bracteosa Belonging to Family Labitae. Am Eurasian J Agric Environ Sci. 2009;6(6):651-656.

20. Anis M, Faisal M. In vitro regeneration and mass multiplication of Psoralea corylifolia - an endangered medicinal plant. Indian J Biotechnol. 2005;4(2):261-264.

21. Cano-Castillo M, Serrano-Martínez F, Casas JL. In vitro propagation of Astragalus nitidiflorus (Leguminosae), an endemic and endangered species from South-East of Spain. Acta Hortic. 2009;812:545-550.
22. Karuppusamy S, Kiranmai C, Aruna V, Pullaiah T. Micropropagation of Vanasushava pedata - an endangered medicinal plant of South India. Plant Tissue Cult Biotechnol. 2006;16(2):85-94.

23. Manjkhola S, Dhar U, Joshi M. Organogenesis, embryogenesis, and synthetic seed production in Arnebia euchroma - a critically endangered medicinal plant of the Himalaya. In Vitro Cell Dev Biol Plant. 2005;41(3):244-248.

24. Erisen S, Yorgancilar M, Atalay E, Babaoglu M, Duran A. Callus induction and plant regeneration of the endemic Astragalus nezaketae in Turkey. Electron J Biotechnol. 2010;13(6):13-14.

25. Ali M, Abbasi BH. Thidiazuron-induced changes in biomass parameters, total phenolic content, and antioxidant activity in callus cultures of Artemisia absinthium L. Appl Biochem Biotechnol. 2014;172(5):2363-2376.

26. Murashige T, Skoog F. A revised medium for rapid growth and bio assays with tobacco tissue cultures. Physiol Plant. 1962;15(3):473-497.

27. Velioglu YS, Mazza G, Gao L, Oomah BD. Antioxidant activity and total phenolics in selected fruits, vegetables, and grain products. $J$ Agric Food Chem. 1998;46(10):4113-4117.

28. Chang CC, Yang M-H, Wen H-M, Chern J-C. Estimation of total flavonoid content in propolis by two complementary colorimetric methods. J Food Drug Anal. 2002;10(3):178-182.

29. Arokiyaraj S, Arasu MV, Vincent S, et al. Rapid green synthesis of silver nanoparticles from Chrysanthemum indicum L. and its antibacterial and cytotoxic effects: an in vitro study. Int J Nanomed. 2014;9:379.

30. Duncan DB. Multiple range and multiple F tests. Biometrics. 1955;11(1): $1-42$.

31. Kovacs E. Regulation of karyotype stability in tobacco tissue cultures of normal and tumorous genotypes. Theor Appl Gen. 1985;70(5): 548-554.

32. Anis M, Varshney A, Siddique I. In vitro clonal propagation of Balanites aegyptiaca (L.) Del. Agroforest Syst. 2010;78(2):151-158.

33. Pradhan C, Kar S, Pattnaik S, Chand P. Propagation of Dalbergia sissoo Roxb through in vitro shoot proliferation from cotyledonary nodes. Plant Cell Rep. 1998;18(1-2):122-126.

34. Das A, Kesari V, Rangan L. Plant regeneration in Curcuma species and assessment of genetic stability of regenerated plants. Biol Plant. 2010;54(3):423-429.

35. Loc NH, Duc DT, Kwon TH, Yang MS. Micropropagation of zedoary (Curcuma zedoaria Roscoe)-a valuable medicinal plant. Plant Cell Tissue Organ Cult. 2005;81(1):119-122.

36. Lata H, Chandra S, Khan I, ElSohly MA. Thidiazuron-induced highfrequency direct shoot organogenesis of Cannabis sativa L. In Vitro Cell Dev Biol Plant. 2009;45(1):12-19.

37. Tiwari V, Tiwari KN, Singh BD. Comparative studies of cytokinins on in vitro propagation of Bacopa monniera. Plant Cell Tissue Organ Cult. 2001;66(1):9-16.

38. Chaohua C, Gonggu Z, Lining Z, et al. A rapid shoot regeneration protocol from the cotyledons of hemp (Cannabis sativa $\mathrm{L}$.). Ind Crops Prod. 2016;83:61-65.

39. Pandey V, Agrawal V. Efficient micropropagation protocol of Spilanthes acmella L. possessing strong antimalarial activity. In Vitro Cell Dev Biol Plant. 2009;45(4):491-499.

40. Singh I, Tiwari K. Evaluation of cotyledonary node of Clitoria rematea $\mathrm{L}$. for high frequency in vitro axillary shoot proliferation. Asian J Plant Sci. 2010;9(6):351-357.

41. Jha AK, Prasad K, Prasad K, Kulkarni A. Plant system: nature's nanofactory. Colloids Surf B Biointerfaces. 2009;73(2):219-223.

42. Qu D, Sun W, Chen Y, Zhou J, Liu C. Synthesis and in vitro antineoplastic evaluation of silver nanoparticles mediated by Agrimoniae herba extract. Int J Nanomed. 2014;9:1871.

43. Kumar R, Roopan SM, Prabhakarn A, Khanna VG, Chakroborty S. Agricultural waste Annona squamosa peel extract: biosynthesis of silver nanoparticles. Spectrochim Acta Part A Mol Biomol Spectrosc. 2012; 90:173-176.

44. Mie R, Samsudin MW, Din LB, Ahmad A, Ibrahim N, Adnan SN. Synthesis of silver nanoparticles with antibacterial activity using the lichen Parmotrema praesorediosum. Int J Nanomed. 2014;9:121. 
45. Gogoi N, Babu PJ, Mahanta C, Bora U. Green synthesis and characterization of silver nanoparticles using alcoholic flower extract of Nyctanthes arbortristis and in vitro investigation of their antibacterial and cytotoxic activities. Mater Sci Eng C Mater Biol Appl. 2015;46: 463-469.

46. Sheshadri SA, Sriram S, Balamurugan P, et al. Melatonin improves bioreductant capacity and silver nanoparticles synthesis using Catharanthus roseus leaves. RSC Adv. 2015;5(59):47548-47554.

47. Vinila VS, Jacob R, Mony A, et al. XRD studies on nano crystalline ceramic superconductor $\mathrm{PbSrCaCuO}$ at different treating temperatures. Crystl Struct Theor Appl. 2014;3:1-9.

48. Noruzi M, Zare D, Khoshnevisan K, Davoodi D. Rapid green synthesis of gold nanoparticles using Rosa hybrida petal extract at room temperature. Spectrochim Acta Part A Mol Biomol Spectros. 2011; 79(5):1461-1465.

49. Muniyappan N, Nagarajan N. Green synthesis of silver nanoparticles with Dalbergia spinosa leaves and their applications in biological and catalytic activities. Process Biochem. 2014;49(6):1054-1061.
50. Ullah R, Khader JA, AbdEIslam NM. Chemical constituents from Phlomis bracteosa. Life Sci J. 2013;10(7s).

51. Bar H, Bhui DK, Sahoo GP, Sarkar P, De SP, Misra A. Green synthesis of silver nanoparticles using latex of Jatropha curcas. Colloids Surf A Physicochem Eng Asp. 2009;339(1-3):134-139.

52. Rao KJ, Paria S. Green synthesis of silver nanoparticles from aqueous Aegle marmelos leaf extract. Mater Res Bull. 2013;48(2):628-634.

53. Ahmad T. Reviewing the tannic acid mediated synthesis of metal nanoparticles. J Nanotechnol. 2014;2014:11.

54. Anjum S, Abbasi BH. Thidiazuron-enhanced biosynthesis and antimicrobial efficacy of silver nanoparticles via improving phytochemical reducing potential in callus culture of Linum usitatissimum L. Int $J$ Nanomed. 2016;11:715-728.

55. Chaloupka K, Malam Y, Seifalian AM. Nanosilver as a new generation of nanoproduct in biomedical applications. Trends Biotechnol. 2010;28(11):580-588.
International Journal of Nanomedicine

\section{Publish your work in this journal}

The International Journal of Nanomedicine is an international, peerreviewed journal focusing on the application of nanotechnology in diagnostics, therapeutics, and drug delivery systems throughout the biomedical field. This journal is indexed on PubMed Central, MedLine, CAS, SciSearch $®$, Current Contents $\AA /$ Clinical Medicine,

\section{Dovepress}

Journal Citation Reports/Science Edition, EMBase, Scopus and the Elsevier Bibliographic databases. The manuscript management system is completely online and includes a very quick and fair peer-review system, which is all easy to use. Visit http://www.dovepress.com/ testimonials.php to read real quotes from published authors.

Submit your manuscript here: http://www.dovepress.com/international-journal-of-nanomedicine-journal 